\title{
The East Aegean Sea strong earthquake sequence of October-November 2005: lessons learned for earthquake prediction from foreshocks
}

\author{
G. A. Papadopoulos, I. Latoussakis, E. Daskalaki, G. Diakogianni, A. Fokaefs, M. Kolligri, K. Liadopoulou, \\ K. Orfanogiannaki, and A. Pirentis \\ Institute of Geodynamics, National Observatory of Athens, 11810 Athens, Greece \\ Received: 18 July 2006 - Revised: 28 September 2006 - Accepted: 28 September 2006 - Published: 11 October 2006
}

\begin{abstract}
The seismic sequence of October-November 2005 in the Samos area, East Aegean Sea, was studied with the aim to show how it is possible to establish criteria for (a) the rapid recognition of both the ongoing foreshock activity and the mainshock, and (b) the rapid discrimination between the foreshock and aftershock phases of activity. It has been shown that before the mainshock of 20 October 2005, foreshock activity is not recognizable in the standard earthquake catalogue. However, a detailed examination of the records in the SMG station, which is the closest to the activated area, revealed that hundreds of small shocks not listed in the standard catalogue were recorded in the time interval from 12 October 2005 up to 21 November 2005. The production of reliable relations between seismic signal duration and duration magnitude for earthquakes included in the standard catalogue, made it possible to use signal durations in SMG records and to determine duration magnitudes for 2054 small shocks not included in the standard catalogue. In this way a new catalogue with magnitude determination for 3027 events was obtained while the standard catalogue contains 1025 events. At least 55 of them occurred from 12 October 2005 up to the occurrence of the two strong foreshocks of 17 October 2005. This implies that foreshock activity developed a few days before the strong shocks of 17 October 2005 but it escaped recognition by the routine procedure of seismic analysis. The onset of the foreshock phase of activity is recognizable by the significant increase of the mean seismicity rate which increased exponentially with time. According to the least-squares approach the $b$-value of the magnitude-frequency relation dropped significantly during the foreshock activity with respect to the $b$-value prevailing in the declustered background seismicity. However, the maximum likelihood approach does not indicate such a drop of $b$. The $b$-value found for the aftershocks that followed
\end{abstract}

Correspondence to: G. A. Papadopoulos

(g.papad@gein.noa.gr) the strong shock of 20 October 2005 is significantly higher than in foreshocks. The significant aftershock-foreshock difference in $b$-value is valid not only if the entire aftershock sequence is considered but also if only the segment of aftershocks that occurred within the first 24-h or the first 48-h after the mainshock of 20 October 2005 are taken into account. This difference in $b$-value should be examined further in other foreshock-aftershock sequences because it could be used as a diagnostic of the mainshock occurrence within a few hours after its generation.

\section{Introduction}

During periods of strong seismic activity in a particular area one of the main issues that civil protection authorities request from scientists to evaluate regards the rapid recognition of the nature of the several phases of seismic activity: foreshocks, mainshock, aftershocks. As for the foreshock phase it is of great importance to recognize it before the mainshock occurrence for the advice of the authorities as for the need to organize counter-measures in view of the impending mainshock. The importance of this problem because of its connection with earthquake prediction has been already noted (e.g. Lombardi, 2003). However, foreshocks precede only some mainshocks and not others. In addition, no standard methodology has been established so far for the on time discrimination between foreshocks and other types of activity like swarms and aftershocks. On the other hand, the rapid decision that a particular strong shock of the sequence is the mainshock is difficult and should be based on certain discrimination criteria. As an instance, the rapid recognition that the system passed from the phase of foreshocks to the phase of aftershocks could be such a criterion.

On 17 October 2005 two strong shocks of magnitudes $M_{w}=5.5$ and $M_{w}=5.8$ ruptured the area to the north of Samos Island (Greece), East Aegean Sea (Fig. 1) (Table 1). On

Published by Copernicus GmbH on behalf of the European Geosciences Union. 


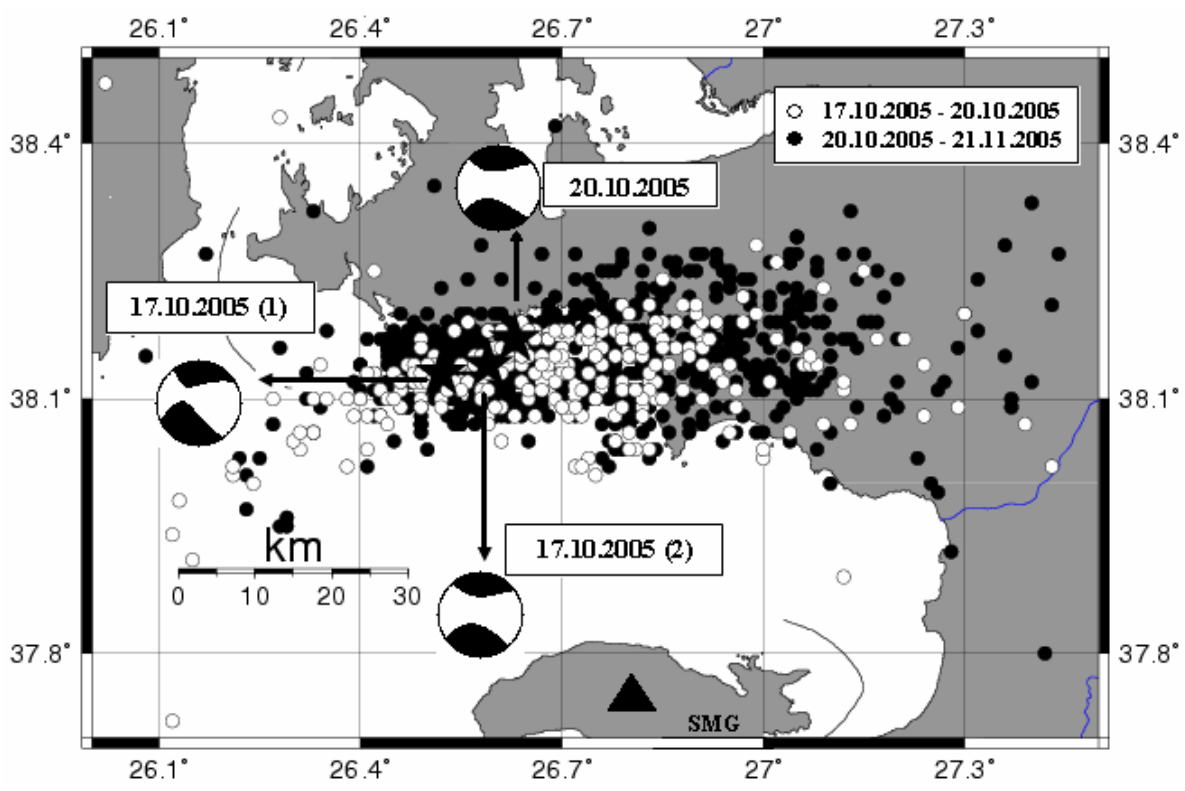

Fig. 1. Foreshocks and aftershocks listed in the NOAGI catalogue (http://www.gein.noa.gr) for the area of Samos Island during OctoberNovember 2005. SMG is the Samos station. Stars indicate the three largest shocks (Table 1). CMT focal mechanisms are determined by Harvard.

Table 1. Focal Parameters of the three largest shocks that occurred in the area of Samos Island (Fig. 1) during October 2005. All parameters are according to the NOAGI determinations (http://www.gein.noa.gr). Magnitudes determined by USGS and Harvard (HRV) are also included.

\begin{tabular}{|c|c|c|c|c|c|c|}
\hline Date (d m y) & Time (GMT) & Lat $\left(\mathrm{N}^{\circ}\right)$ & Long $\left(\mathrm{E}^{\circ}\right)$ & $\begin{array}{l}\text { Magnitude } \\
\text { USGS }\end{array}$ & NOAGI & HRV \\
\hline 17 Oct 2005 & $05: 45: 16$ & 38.14 & 26.59 & $5.7\left(M_{L}\right)$ & $5.5\left(M_{L}\right)$ & $5.5\left(M_{w}\right)$ \\
\hline 20 Oct 2005 & 21:40:04 & 38.15 & 26.63 & $5.9\left(M_{w}\right)$ & $5.6\left(M_{L}\right)$ & $5.8\left(M_{w}\right)$ \\
\hline
\end{tabular}

20 October 2005 another strong earthquake of $M_{w}=5.8$ or $M_{w}=5.9$ ruptured the same area. The earthquake activity continued with decreasing rate up to the end of November 2005. Hundreds of earthquakes recorded by the national seismograph network of the National Observatory of Athens, Institute of Geodynamics (NOAGI), Greece. The earthquake sequence was dominated by nearly E-W dextral strike-slip motion and extended in both the Greek and Turkish territories. For reasons of simplicity, however, the area considered in this study (Fig. 1) is referred to as "Samos area".

The earthquake activity did not caused serious damage in the area. However, a great concern was generated to the local population as for the possible occurrence of a large shock. The main question that scientists but also the authorities faced with was about the nature of the ongoing activity: were the strong shocks of 17 October 2005 and 20 October 2005 foreshocks of an impending stronger earthquake or one of those events was the mainshock? Such questions were impossible to be replied reliably on a near real-time ba- sis not only due to that magnitudes determined by NOAGI at that time were only preliminary but also because of the lack of certain discrimination criteria between foreshocksmainshock-aftershocks on near real-time conditions.

In this paper we study the October-November 2005 earthquake sequence in Samos area. Based on seismicity statistical properties it is shown how a methodology could be established for the rapid recognition (a) of the foreshock phase of activity, and (b) of the mainshock occurrence of an earthquake sequence. Some general properties of the foreshock sequences, however, are firstly reviewed.

\section{Properties of foreshocks}

Foreshock sequences are characterized by some distinct features. Laboratory material fracture experiments (e.g. Mogi, 1963; Scholz, 1968) along with numerical modeling in spring-block models (Hainzl et al., 1999) have shown a clear acceleration of the fracturing process before the main 
fracture. Studies regarding seismicity in Japan, western United States, Greece, Italy and elsewhere verified this in nature showing that foreshock activity increases approximately as the inverse of time before mainshock (Papazachos, 1975; Kagan and Knopoff, 1978; Jones and Molnar, 1979). In the magnitude-frequency or Gutenberg-Richter (G-R) relation

$\log N=a-b M$

the parameter $b$ drops and becomes significantly lower in foreshocks than in aftershocks or in background seismicity (Mogi, 1963; Scholz, 1968; Papazachos, 1975; Jones and Molnar, 1979; Hainzl et al., 1999; Molchan et al., 1999); where $N$ is the incremental or the cumulative number of events of magnitude $\geq M \pm \Delta M$ and $a, b$ are parameters determined by the data (Gutenberg and Richter, 1944). Foreshocks occur from hours to a few months, and very rarely about 1.5 years before the mainshock (Jones, 1984; Jones and Molnar, 1979; Molchan et al., 1999; Papadopoulos et al., 2000; Sobolev, 2000). A common knowledge is that foreshocks precede only some mainshocks and not others. However, this may be only an apparent result given that low magnitude foreshocks usually are not listed in standard earthquake catalogues due to that the magnitude cut-off in such catalogues is relatively high.

\section{Construction of new earthquake catalogue}

Examination of the standard earthquake catalogue produced by the NOAGI routine procedure of seismic analysis (http: //www.gein.noa.gr) showed that in the Samos area no apparent seismicity increase occurred before the first strong shock of 17 October 2005. The catalogue lists three shocks that took place at a distance of less than $30 \mathrm{~km}$ from the epicenters of the 17 October 2005 strong earthquakes: one shock of magnitude 3.0 on 21 August 2005 and two shocks of magnitude 3.1 and 3.2 on 16 October 2005. The activity increased drastically only after the strong events of 17 October 2005. Therefore, based on the standard catalogue of the area one may conclude that the first strong shock of 17 October 2005 came without foreshock notice. On the contrary, after the two earthquakes of 17 October 2005 many sizeable shocks were recorded, analyzed and listed in the standard NOAGI catalogue. Should the strong shock of 20 October 2005 be considered as the mainshock of the October-November 2005 sequence in Samos area then the standard catalogue implies that foreshock activity appeared only from 17 October 2005 onwards.

To investigate small foreshocks that possibly escaped the routine determination and cataloguing we analyzed the records of the Samos (SMG) station, which is the closest to the activated area. In the daily procedure of seismic analysis NOAGI determines focal parameters for every earthquake event that occurs in Greece and the adjacent regions provided that at least three $\mathrm{P}$ and/or $\mathrm{S}$ phases are readable from its national seismograph network. NOAGI routinely produces signal duration magnitude, $M_{D \text { (cat) }}$, as the average of the $M_{D}$ 's measured in the stations that record an earthquake. In addition, local magnitude, $M_{L}$, is routinely produced when records in both the north-south and east-west components of the Wood-Anderson instrument operating in Athens (ATH) station are available.

Examination of the digital and analog records of SMG station revealed that from 12 to 17 October 2005 a number of 52 shocks were recorded. As mentioned above only three of them are listed in the standard catalogue. However, all the shocks are characterized by a S-P difference of $\sim 6-$ $8 \mathrm{~s}$, which corresponds to an average epicentral distance of $50 \mathrm{~km}$. This is also the average epicentral distance of the activated area of Samos from the SMG station. Because of this and since no activity was noted at that time in a different area to distance of about $50 \mathrm{~km}$ away from SMG, we assume that these small shocks were generated in the Samos area and, therefore, they were foreshocks that preceded the strong activity of 17 October 2005. A similar examination showed that hundreds of small shocks were recorded in SMG station after the origin of the first shock of 17 October 2005. These shocks, however, are not listed in the standard catalogue.

Duration magnitudes, $M_{D}$, which are in use by NOAGI are determined from relations of the form (e.g. Papanastassiou, 1989)

$M_{D}=a+b \log D+c \Delta$

where $D$ is signal duration, $\Delta$ is epicentral distance and $a$, $b, c$ are parameters. For small epicentral distances the term $c \Delta$ can be neglected from Eq. (2). For the estimation of duration magnitude, $M_{D \text { (est) }}$, of the small shocks recorded in SMG but not listed in the standard catalogue for the period from 12 October to 21 November 2005, we firstly produced the linear relationship (Fig. 2):

$M_{D(\text { cat })}=1.41 \log D+0.68, R^{2}=0.888$

from 953 earthquakes that occurred in Samos area in the above time interval and are listed in the NOAGI standard catalogue; where $D$ is signal duration in SMG station and $M_{D \text { (cat) }}$ is duration magnitude in the standard catalogue. For 87 out of 953 events local magnitude is also determined. For these 87 shocks the duration and local magnitudes are correlated well (Fig. 2):

$M_{L}=1.06 M_{D(\mathrm{cat})}-0.16, R^{2}=0.865$

which implies that $M_{D \text { (cat) }}$ is equivalent to $M_{L}$. The term $c$ $\Delta$ has been neglected from Eq. (3) because $\Delta$ is small.

For the application of Eq. (3) signal duration of small shocks recorded only in SMG was measured for signal amplitude $\geq 1 \mathrm{~mm}$. This procedure resulted with the estimation of duration magnitude, $M_{D \text { (est) }}$, for 2054 small events that occurred in Samos area from 12 October to 21 November 2005. To check the reliability of the magnitude $M_{D \text { (est) }}$ a relationship was investigated between $M_{D \text { (est) }}$ and $M_{D \text { (cat) }}$ for 

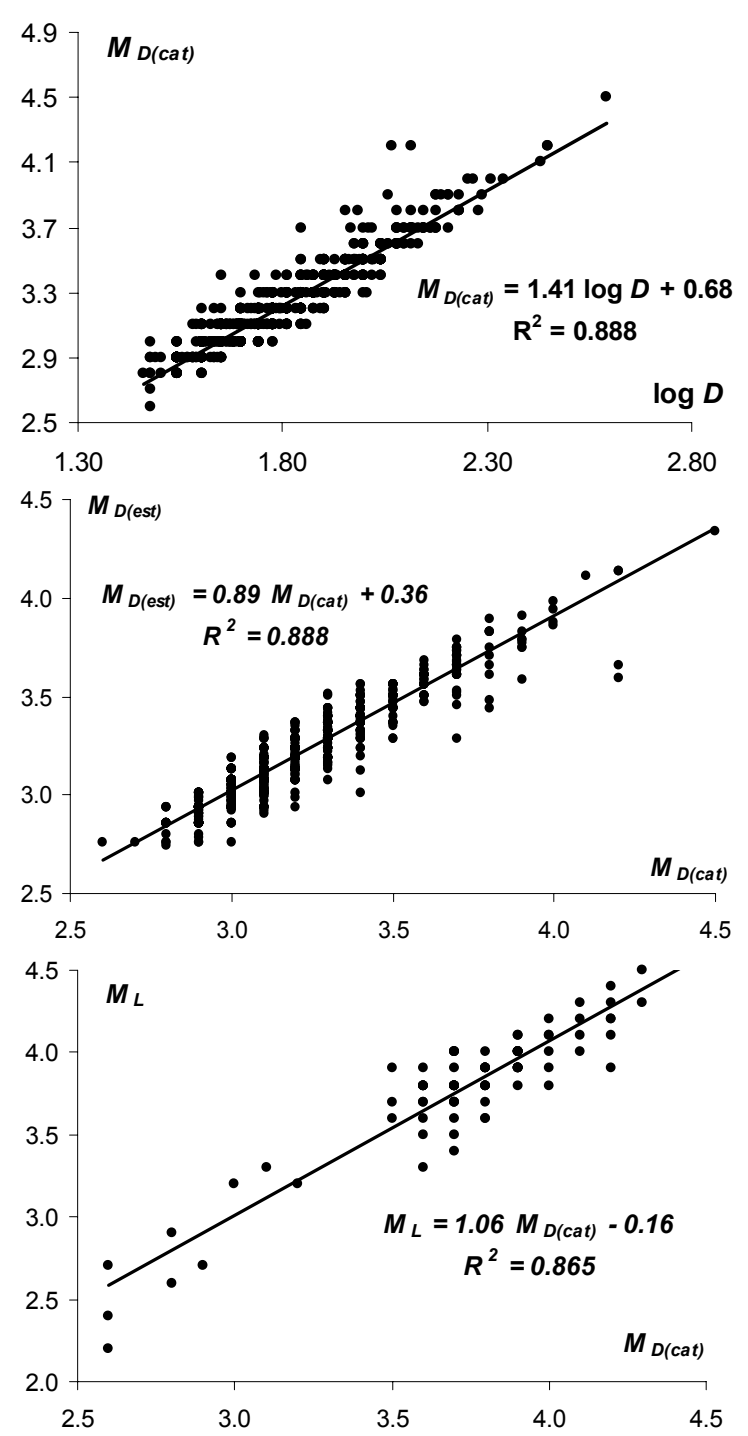

Fig. 2. Top: Duration magnitude, $M_{D \text { (cat) }}$, versus the logarithm of the signal duration, $\log D$, for the events listed in the NOAGI standard catalogue for the Samos area for the time interval from 12 October 2005 to 21 November 2005.

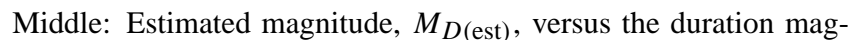
nitude, $M_{D \text { (cat) }}$, provided by the NOAGI standard catalogue, for the Samos area for the time interval from 12 October 2005 to 21 November 2005. The reliability of the estimated duration magnitude, $M_{D \text { (est) }}$, is indicated by the coefficient of the duration magnitude, $M_{D \text { (cat) }}$, in the linear relationship. The closer this coefficient is to 1 the more the $M_{D \text { (est) }}$ magnitude approximates the $M_{D \text { (cat) }}$ magnitude.

Bottom: Local magnitude, $M_{L}$, versus duration magnitude, $M_{D \text { (cat) }}$, for the events listed in the NOAGI standard catalogue for the Samos area for the time interval from 12 October 2005 to 21 November 2005.

$R$ is the correlation coefficient of the line fitting the data. the 953 out of 2054 events listed in the catalogue. The relationship found (Fig. 2)

$M_{D(\text { est })}=0.89 M_{D(\text { cat })}+0.36, R^{2}=0.888$

implies that $M_{D \text { (est) }}$ and $M_{D \text { (cat) }}$ are well correlated. In this way a new catalogue was obtained where the number of earthquakes with determined magnitudes is drastically increased with respect to the number of earthquakes inserted in the standard NOAGI catalogue. Although this new catalogue provides time of occurrence and magnitude determination but not epicentral estimations, yet allows for a reliable statistical treatment of the October-November seismic sequence in Samos area. In fact, in the new catalogue magnitude determination was obtained for 3027 events while the standard catalogue contains 1025 events for the time interval from 17 October to 21 November 2005. As for the time interval from 12 October to 17 October 2005 the number of events increased from 3 in the standard catalogue to 55 in the new catalogue.

\section{Statistical properties of the October-November 2005 seismic sequence}

From the magnitude determinations listed in Table 1 it comes out that the largest event in the earthquake sequence of Samos area possibly was that of 20 October 2005 and, therefore, the hypothesis that this event was the mainshock of the earthquake sequence becomes plausible. This is also supported by the temporal evolution of activity in the Samos area in the time interval from 12 October to 21 November 2005. The strong earthquake of 20 October 2005 was preceded by exponentially increasing foreshock activity since at least the 12 October 2005 (Fig. 3). In fact, the activity increased exponentially from 12 October 2005 up to 17 October 2005 inclusive. A relative drop of the activity was temporary noted from 18 October 2005 up to the occurrence of the strong shock of 20 October 2005. The time distribution of the activity that followed this shock up to 21 November 2005 fits well the Omori law (Fig. 4) which implies that this phase of activity represents a typical aftershock sequence.

This hypothesis was examined further by comparing the statistical properties of the foreshock period with the statistical properties of the background seismicity and the aftershock period. For the identification of the background seismicity of the Samos area the standard catalogue from 1 January 1984 up to 31 December 2005 was considered (data are derived from the catalogue in http://www.gein.noa.gr). The time interval starts on 1 January 1984 since that date signifies the beginning of routine computerized earthquake determination and cataloguing by NOAGI. The residual catalogue that remained after a declustering procedure was considered to represent the background seismicity of Samos area. Declustering was performed by removing dependent events on the basis of a Greek version of the Gardner and Knopoff (1974) 
Table 2. Seismicity rate, $r$ (events/day, 1 day $=24 \mathrm{~h}$ ), and b-values determined for background seismicity (1), foreshock period (2), and aftershock period (3). $b_{l s}$ and $b_{m l}$ are b-values determined by the least-squares and maximum likelihood approaches, respectively. $P$ is the probability that the two samples come from the same population according to the Utsu (1999) test. $a$ is the significance level of the difference of the two samples according to the t-test.

\begin{tabular}{|c|c|c|c|c|c|c|}
\hline Time intervals & $b_{l s}$ & $P$ & $b_{m l}$ & $P$ & $r$ & $a$ \\
\hline (1) 1 Jan $1996-11$ Oct 2005 & 1.32 & & 0.91 & & 0.07 & \\
\hline (2) 12 Oct $2005-20$ Oct 2005 & 1.10 & 0.013 & 1.45 & $2.16 \times 10^{-11}$ & 55 & 0.01 \\
\hline (3) 20 Oct $2005-21$ Nov 2005 & 1.83 & $6.64 \times 10^{-26}$ & 1.67 & 0.005 & 13 & 0.01 \\
\hline
\end{tabular}

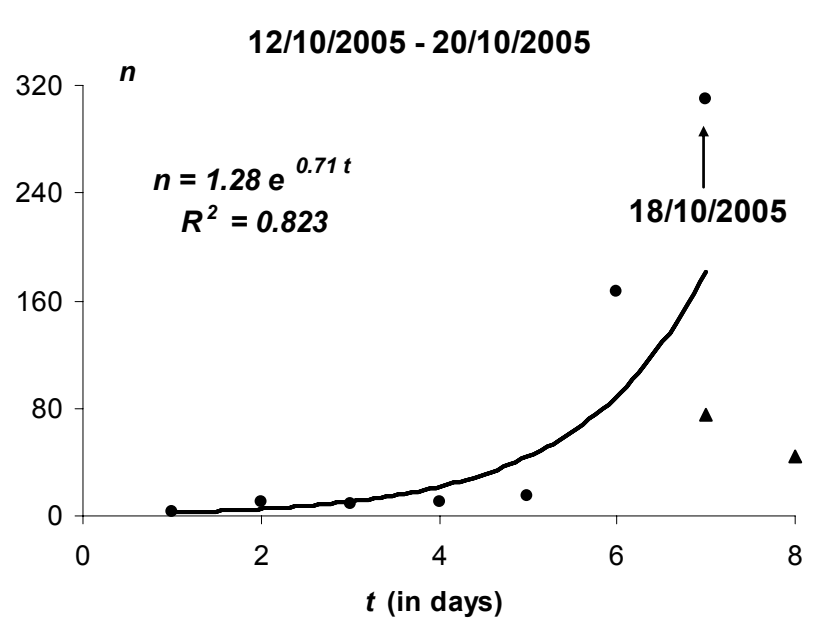

Fig. 3. Time distribution of the foreshock activity that preceded the mainshock of 20 October 2005. Time $\mathrm{t}=0$ is 00:00:00 a.m. of 12 October 2005. $n$ is event frequency per day $(1$ day $=24 \mathrm{~h})$. Exponential curve is the best fit. $R$ as in Fig. 2. A power-law increase of the activity prevails from 12 October 2005 up to 18 October 2005 (solid circles). However, in the last two days a relative drop of the activity is noted (solid triangles).

algorithm (Latoussakis and Stavrakakis, 1992). The initial catalogue contains 1758 seismic events while the declustered catalogue contains 411 events. Completeness analysis with the G-R diagram showed that the magnitude cut-off is $M_{L}=3.4$ from 1 January 1984 onwards but it is $M_{L}=3.1$ for 1 January 1996 (Fig. 5 top). However, for the interval from 12 October 2005 to 21 November 2005 the magnitude cut-off is $M_{L}=2.9$ (Fig. 5 middle and down).

Statistical properties were examined for three main periods of activity for a common magnitude cut-off $M_{L}=3.1$ : (1) period of background seismicity from 1 January 1996 to 11 October 2005, (2) period of foreshock activity from 12 October 2005 to 20 October 2005, (3) period of aftershock activity from to 20 October 2005 to 21 November 2005. Time interval 2 terminates with the last shock that preceded the strong earthquake of 20 October 2005, while time interval 3 starts with the first shock that follows the strong earthquake of 20 October 2005.
$20 / 10 / 2005-21 / 11 / 2005$

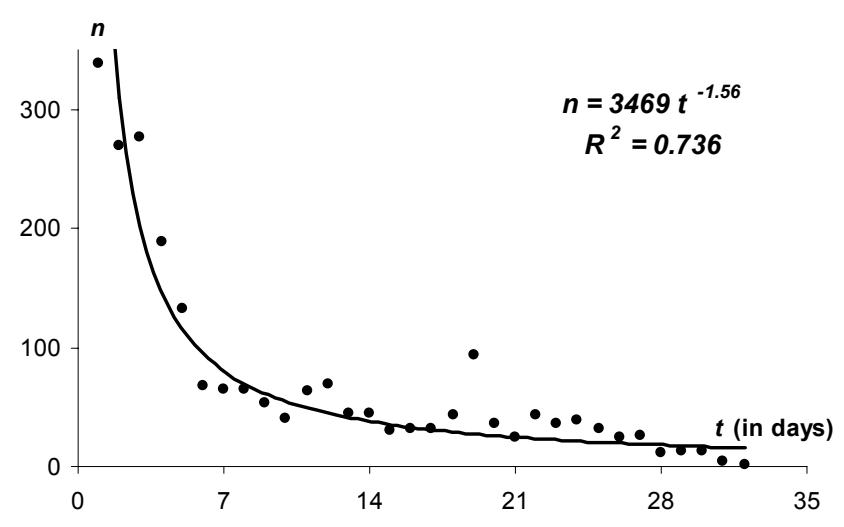

Fig. 4. Time distribution of the aftershock activity developed in Samos area after the occurrence of the strong shock of 20 October 2005. The data fit well the original Omori law. $R$ and $n$ as in Fig. 2 and Fig. 3, respectively. Time $\mathrm{t}=0$ is the origin time of the mainshock of 20 October 2005.

For each one time interval two parameters were calculated: the mean seismicity rate, $r$ (in events/day, where 1 day $=$ $24 \mathrm{~h}$ ) and the $b$-value of the magnitude-frequency (or G-R) relation. Parameter $b$ was determined from both the leastsquares approach and the maximum likelihood method developed by Aki (1965) and Utsu $(1965,1966)$.

For reasons of compatibility the seismicity rate for all time intervals examined was calculated for $M_{L} \geq 3.1$. Mean seismicity rate equal to only 0.07 events/day (Table 2 ) was found for the time interval of background seismicity. The mean seismicity rate increased drastically to 55 events/day during the foreshock time period from 12 October 2005 to 20 October 2005. However, it was equal to about 6 events/day during the early foreshock phase from 12 October 2005 to 17 October 2005. After the strong shock of 20 October 2005 the rate increased further to 160 events/day and 105 events/day during the first 24-h and the first 48-h time intervals of the aftershock period, respectively. However, the mean seismicity rate was 13 events/day during the entire aftershock period from 20 October 2005 to 21 November 2005. 
01/01/1996 - 11/10/2005
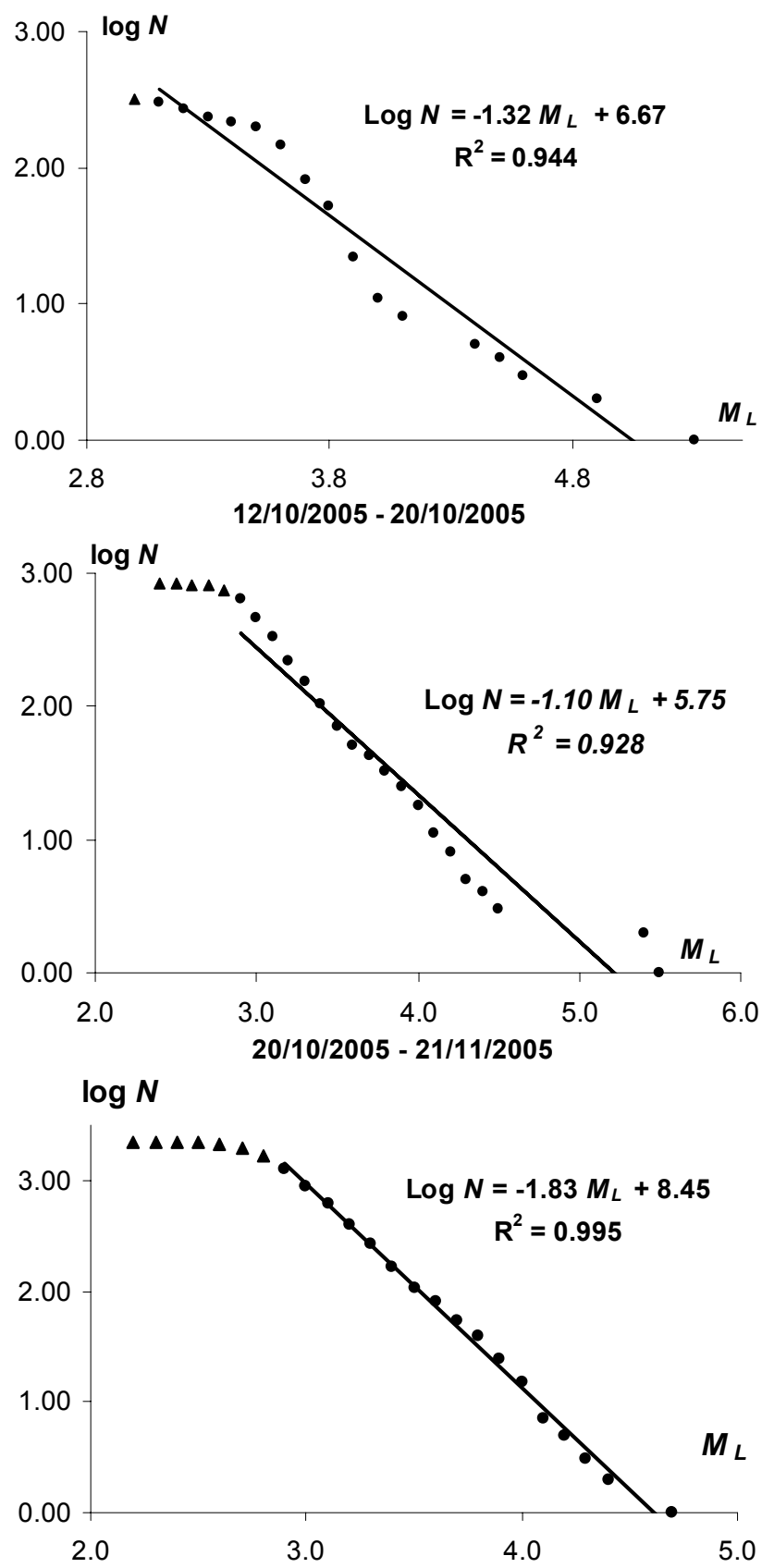

Fig. 5. Magnitude - frequency relation for the Samos area for background seismicity (top), foreshock period (middle) and aftershock period (down). $N=$ cumulative number of events, $M_{L}=$ local magnitude or equivalent duration magnitude. $R$ as in Fig. 2.

The $b$-value changes significantly from one time interval to the other but for a given time interval it varies depending on the method of calculation (Table 2). The significance of $b$-value changes were tested by applying the test proposed by Utsu (1999) who calculates the probability $P$ that the two samples come from the same population. For the time period of declustered background seismicity values of $b_{l s}=1.32$ and $b_{m l}=0.91$ were found by the least-squares and maximum likelihood approaches, respectively. The $b$ values of $b_{l s}=1.10$ and $b_{m l}=1.45$ found for the foreshock period, however, changed significantly with respect to the values found for background seismicity. This is a contradictory result which indicates that according to least-squares $b$ decreases but according to maximum likelihood $b$ increases with respect to the values calculated for the background seismicity. To examine further these contradiction values of $b$ were determined for the time interval which covers the main phase of foreshock activity, which extents from 12 October 2005 up to the generation of the second strong shock of 17 October 2005 inclusive. Values of $b_{l s}=0.60$ and $b_{m l}=0.92$ were found which implies that $b$ again dropped significantly according to least-squares approach but it remained nearly constant according to maximum likelihood approach. The relatively high $b$-values found for the entire foreshock period with respect to the main phase of foreshock activity can be interpreted by that the two strong foreshocks of 17 October 2005 produced their own aftershocks which are incorporated in the entire foreshock period.

Both approaches clearly indicate that in the phase of aftershocks the $b$-value is significantly increased with respect to the main foreshock period as well as with respect to the entire foreshock period. This result is of great importance for the discrimination between the foreshock phase and aftershock phase of a particular earthquake sequence. To show that such a discrimination becomes possible within one or two days after the strong shock and that the strong shock is the mainshock of the sequence we calculated the $b$-value only for the first 24-h and for the first 48-h following the occurrence of the strong shock of 20 October 2005. Values of $b_{l s}=1.34, b_{m l}=1.74$ and $b_{l s}=1.65, b_{m l}=1.74$ were found for the first 24-h and for the first 48-h, respectively. These values are again significantly higher than those found for the foreshock period.

\section{Conclusions}

Statistical properties of the seismic sequence of OctoberNovember 2005 in the Samos area, East Aegean Sea, were studied with the aim to show how it is possible to establish criteria for (a) the rapid recognition of both the ongoing foreshock activity and the mainshock, and (b) the rapid discrimination between the foreshock and aftershock phases of activity. It has been shown that before the mainshock of 20 October 2005 , foreshock activity is not recognizable in the standard earthquake catalogue produced by the routine procedure of daily seismic analysis and cataloguing of the National Observatory of Athens. However, a detailed examination of the records in the SMG station, which is the closest 
to the activated area, revealed that hundreds of small shocks not listed in the standard catalogue were recorded in the time interval from 12 October 2005 up to 21 November 2005. The production of reliable relations between seismic signal duration and duration magnitude for earthquakes included in the standard catalogue, made it possible to use signal durations in SMG records and to determine duration magnitudes for 2054 small shocks not included in the standard catalogue. In this way a new catalogue with magnitude determination for 3027 events was obtained while the standard catalogue contains 1025 events for the time interval from 17 October to 21 November 2005. At least 55 of them occurred from 12 October 2005 up to the occurrence of the two strong foreshocks of 17 October 2005. This implies that foreshock activity developed a few days before the strong shocks of 17 October 2005 but it escaped recognition by the routine procedure of seismic analysis. This case makes a good example on how single station records may increase drastically the number of events recorded and how hidden foreshocks can be revealed.

The onset of the foreshock phase of activity is recognizable by the significant increase of the mean seismicity rate. In fact, the mean background seismicity rate in the declustered catalogue of the period from 1996 to 2005 inclusive is only 0.07 events/day while the mean seismicity rate during the early foreshock phase from 12 October 2005 to 17 October 2005 increased to 6 events/day. The foreshock sequence exhibits an exponential increase of the number of events with time but the last two days before the mainshock a relative drop of foreshock activity is noted.

According to the least-squares approach the $b$-value of the magnitude-frequency relation dropped significantly during the foreshock activity with respect to the $b$-value prevailing in the declustered background seismicity. However, the maximum likelihood approach does not indicate such a drop of $b$. This contradictory result deserves to be examined as for the factors that control it. One possible cause of it is that the catalogue of mainshocks, produced by declustering the initial catalogue, does not entirely satisfies the Gutenberg-Richter law as shown by Lombardi (2003). The $b$-value found for the aftershocks that followed the strong shock of 20 October 2005 is significantly higher than in foreshocks. The significant aftershock-foreshock difference in $b$-value is valid not only if the entire aftershock sequence is considered but also if only the segment of aftershocks that occurred within the first 24-h or the first 48-h after the mainshock of 20 October 2005 are taken into account. This difference in $b$-value should be examined further in other foreshock-aftershock sequences because it could be used as a diagnostic of the mainshock occurrence only a few hours after its generation.

Acknowledgements. This paper is part of the research project Seismic eArly warning For EuRope (SAFER) supported by the CEC, contract number 036935, 6th Framework Programme, FP6-2005-Global-4, Reduction of seismic risks.
Edited by: M. Contadakis

Reviewed by: A. Zavyalov

\section{References}

Aki, K.: Maximum likelihood estimate of $\mathrm{b}$ in the formula $\log \mathrm{N}=\mathrm{a}-$ bM and its confidence limits, Bull. Earthq. Res. Inst., 43, 237239, 1965.

Gardner, J. K. and Knopoff, L.: Is the sequence of earthquakes in Southern California, with aftershocks removed, Poissonian, Bull. Seismol. Soc. Am., 64, 1363-1367, 1974.

Gutenberg, B. and Richter, C.: Frequency of earthquakes in California, Bull. Seismol. Soc. Am., 34, 185-188, 1944.

Hainzl, S., Zöller, G., and Kurths, J.: Similar power laws for foreshock and aftershock sequences in a spring-block model for earthquakes, J. Geophys. Res., 104, 7243-7253, 1999.

Jones, L. M.: Foreshocks (1966-1980) in the San Andreas System, California, Bull. Seismol. Soc. Am., 74, 1361-1380, 1984.

Jones, L. M. and Molnar, P.: Some Characteristics of Foreshocks and their Possible Relationship to Earthquake Prediction and Premonitory Slip on Faults, J. Geophys. Res., 84, 3596-3608, 1979.

Kagan, Y. and Knopoff, L.: Statistical study of the occurrence of shallow earthquakes, Geophys. J. R. Astr. Soc., 55, 67-86, 1978.

Latoussakis, J. and Stavrakakis, G. N.: Times of increased probability of earthquakes of $\mathrm{M}_{L} \geq 5.5$ in Greece diagnosed by algorithm M8, Tectonophysics, 210, 315-326, 1992.

Lombardi, A. M.: The maximum likelihood estimator of $b$-value for mainshocks, Bull. Seismol. Soc. Am., 93, 2082-2088, 2003.

Mogi, K.: The fracture of a semi-infinite body caused by an inner stress origin and its relation to the earthquake phenomena (second paper), Bull. Earthq. Res. Inst., 41, 595-614, 1963.

Molchan, G. M., Kronrod, T. L., and Nekrasona, A. K.: Immediate foreshocks: time variation of the b-value, Phys. Earth Planet. Inter., 111, 229-240, 1999.

National Observatory of Athens, Institute of Geodynamics (NOAGI), Earthquake Catalogue, http://www.gein.noa.gr, 2006.

Papadopoulos, G. A., Drakatos, G., and Plessa, A.: Foreshock Activity as a precursor of strong earthquakes in Corinthos Gulf, Central Greece, Phys. Chem. Earth, 25, 239-245, 2000.

Papanastassiou, D.: Detectability and location of the determination of source parameters of the seismological networks of NOA, PhD thesis, University of Athens, 1989.

Papazachos, B.: Foreshocks and earthquake prediction, Tectonophysics, 28, 213-226, 1975.

Scholz, C. H.: The frequency-magnitude relation of microfracturing in rock and its relation to earthquakes, Bull. Seismol. Soc. Am., 58, 399-415, 1968.

Sobolev, G. A.: Precursory Phases of Large Kamchatkan Earthquakes, Volcanol. Seismol., 21, 497-509, 2000.

Utsu, T.: A method in determining the value of $\mathrm{b}$ in a formula logn =a-bM showing the magnitude frequency for earthquakes, Geophys. Bull. Hokkaido Univ., 13, 99-103, 1965.

Utsu, T.: A statistical significance test for the difference in b-value between two earthquake groups, J. Phys. Earth, 14, 37-40, 1966.

Utsu, T.: Representation and analysis of the earthquake size distribution: a historical review and some new approaches, Pure Appl. Geophys., 155, 509-535, 1999. 